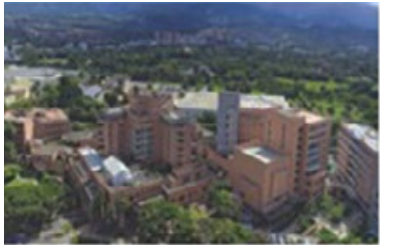

\title{
Hemoptisis Masiva: Curso Clínico, Imágenes, Etiología y Desenlaces en Pacientes Adultos Atendidos en un Hospital de Alta Complejidad: 2011-2017
}

Liliana Fernández-Truillo ${ }^{1,2}$, Juan D. Izquierdo², Daniel Arboleda², Juliana Lores², Diana M. Martínez-Ruiz ${ }^{3,2}$ ${ }_{1}^{1}$ Depto de Medicina Interna, Neumología Intervencionista. ${ }^{2}$ Facultad de Ciencias de la Salud, Universidad Icesi. ${ }^{3}$ Centro de Investigaciones Clínicas, Fundación Valle del Lili. Cali, Colombia.

\section{Introducción}

Hemoptisis masiva, expect. $>400 \mathrm{ml}$ de sangre, árbol traqueo-bronquial $\circ$ parénquima pulmonar. Representa $5 \%$ de hemoptisis, mortalidad $50 \%$ en ausencia de tratamiento adecuado. Puede acompañar enfermedades respiratorias y sistémicas. Etiología variable, enfermedades/pulmonares, anomalías vasc., inflamatorias, iatrogénicas, entre otros. Pocos estudios enfocados en caracterización de hemoptisis masiva en Colombia.

\section{Resultados}

37 pac, promedio/edad 55A, 62.1\%H. Antecedentes/personales: TBC (24.3\%), HTA (21.6\%), neumonía (18.9\%), EPOC y cáncer $(13.5 \% \mathrm{c} / \mathrm{u})$, CPCNP el más frecuente. Síntomas: tos (100\%), disnea (64.7\%), expectoración (58\%). $75.6 \%$ tuvieron tomografía/tórax, vidrio esmerilado (66.6\%), nódulos (50\%), cavitaciones (37\%) y bronquiectasias $(34,6 \%)$. FBO en $67.5 \%$, presentando endobronquitis (56\%) y sangrado activo (44\%). $16.2 \%$ requirieron intervención endovascular, $29.7 \%$ cirugía, lobectomía el procedimiento más frecuente, $8 \%$ manejo endoscópico con broncoscopia terapéutica multimodal. Etiología principal, neumonía adquirida en comunidad $21.6 \%$, seguido de TBC $18.9 \%$. Muerte asociada a hemoptisis $27 \%$, siendo las principales cáncer pulmonar, neumonía asociada a la comunidad y causa desconocida.

\section{Objetivos}

Describir curso clínico, imágenes, etiología y desenlaces de hemoptisis masiva en un hospital de alta complejidad, 2011-2017.

\section{Material y Métodos}

Estudio descriptivo, retrospectivo, $>18 \mathrm{~A}$ con hemoptisis/masiva. Revisión HC con autorización de comité de ética. Variables analizadas: demográficas, clínicas, imágenes, etiología, tratamiento, mortalidad. Análisis estadístico descriptivo, frecuencias/absolutas y porcentajes para variables/cualitativas; las variables/cuantitativas con media o mediana y medidas de dispersión, según distribución de normalidad identificada con prueba de ShapiroWilk. Se utilizó STATAv.12.1\%.

\section{Conclusiones}

La hemoptisis es compleja, requiere atención inmediata, estabilización hemodinámica, protección de VA y Dx multidisciplinario para controlar sangrado, identificar etiología y prevenir futuros eventos. Desenlace peor a mayor edad y comorbilidades, la inf. respiratoria aguda con secuelas previas o enf. activa fueron la causa más frec. de hemoptisis masiva en nuestro estudio y la TBC sigue siendo una causa importante. La mortalidad se asoció a $\mathrm{Ca}$ pulmonar e inf. respiratoria. La FBO para Dx y tto endoscopico multimodal, además de las intervenciones vasculares son herramientas importantes para evaluar, controlar y tratar el sangrado. 